\title{
Alternative Intertemporal Permit Trading Regimes with Stochastic Abatement Costs
}

\author{
Hongli Feng and Jinhua Zhao
}

Working Paper 02-WP 318

November 2002

\author{
Center for Agricultural and Rural Development \\ lowa State University \\ Ames, lowa 50011-1070 \\ www.card.iastate.edu
}

Hongli Feng is an assistant scientist at the Center for Agricultural and Rural Development, lowa State University. Jinhua Zhao is an assistant professor in the Department of Economics, lowa State University.

The authors thank John Beghin, David Hennessy, Brent Hueth, and Cathy Kling for insightful comments. Errors and ommissions are the responsibility of the authors.

This publication is available online on the CARD website: www.card.iastate.edu. Permission is granted to reproduce this information with appropriate attribution to the authors and the Center for Agricultural and Rural Development, lowa State University, Ames, lowa 50011-1070.

For questions or comments about the contents of this paper, please contact Hongli Feng, 560D Heady Hall, lowa State University, Ames, IA 50011-1070; Ph: 515-294-6307; Fax: 515-294-6336; E-mail: hfeng@iastate.edu.

lowa State University does not discriminate on the basis of race, color, age, religion, national origin, sexual orientation, sex, marital status, disability, or status as a U.S. Vietnam Era Veteran. Any persons having inquiries concerning this may contact the Office of Equal Opportunity and Diversity, 1031 Wallace Road Office Building, Room 101, 515-294-7612. 


\begin{abstract}
We examine the social efficiency of alternative intertemporal permit trading regimes. Banking with a 1-to-1 ratio and with a non-unitary intertemporal trading ratio (ITR) are compared with each other and with the no-banking permit trading regime. The more industry-wide shocks vary, and/or the more they are negatively correlated across time, the more efficient is a bankable permit regime. When the slope of the benefit function is greater than the slope of the damage function, banking with ITR $=1+\mathrm{r}$ is more efficient than a no-banking regime. Banking with $\mathrm{ITR}=1$ can be more efficient than a no-banking regime. However, whether $\mathrm{ITR}=1$ or $\mathrm{ITR}=1+\mathrm{r}$ is better depends on the covariance structure of the shocks and the benefit and damage functions.
\end{abstract}

Key words: bankable permits, permit banking and borrowing

JEL Classification: Q2, Q28 


\section{Alternative Intertemporal Permit Trading Regimes with Stochastic Abatement Costs}

\section{Introduction}

In recent years, we have witnessed increasing interest in the use of tradable permit systems adopted by the United States and an increasing number of nations for pollution control. While most permit systems focus on the flexibility provided by trading among or within emitting sources, the flexibility provided by trading across time also has been considered. Temporal permit trading may include banking and borrowing. Banking occurs when permits authorized for the current period are saved for use in some subsequent period. Borrowing occurs when permits authorized for some future period are instead used in the current period. Temporal trading can lower compliance costs by allowing firms to hedge against risks in emissions patterns and smooth out fluctuations in abatement costs over time. Stavins (2002) and Tietenberg (2001) both recognize that the temporal dimension can be a key component of a permit trading system.

In fact, banking has played an important role in some pollution control programs. For example, banking has likely enhanced the performance of the $\mathrm{SO}_{2}$ allowance trading program (Ellerman et al., 2000), the U.S. lead rights trading program a decade earlier (Kerr and Maré, 1996) and the control of automobile hydrocarbon emissions in California (Rubin and Kling, 1993). Examples of other programs that have made use of bankable permits include the Corporate Average Fuel Economy standards for automobiles and light trucks, which allowed banking and, in some cases, borrowing (Farrell et al., 1999); the Ozone Transport Region 
$\mathrm{NO}_{x}$ and VOCs emission trading program, which allowed banking; and, as an example of state-level programs, the Delaware $\mathrm{NO}_{x}$ and VOCs emission trading program, which also allowed banking. ${ }^{1}$

In spite of the potential for application of bankable permits, and the extensive studies on permit trading, there is limited research on the efficiency of bankable permits. Much of the literature on tradable permit systems has focused on the cost effectiveness of these pollution control mechanisms. Most economists now agree that permit trading, including bankable permit programs, can be cost effective (Tietenberg, 2001; Cronshaw and Kruse, 1996; and Rubin, 1996).

While separating means (cost-effective instruments) from ends (efficiency) highlights a strength of permit trading systems, there are limitations to this wisdom. As Stavins (1998) notes, "one risks designing a fast train to the wrong station." Kling and Rubin (1997) demonstrate the risks from focusing on cost effectiveness by showing that, in a bankable permit system, firms will choose suboptimally excessive emissions in early periods and correspondingly too few in later periods. Leiby and Rubin (2001) extend their study to stock pollutants. Neither of these two models considers the consequences of incomplete information.

However, with complete information, there is no real advantage to permit trading, either across time or across firms, since the regulator can set the optimal number of permits for each firm in each period. Thus, it is important to analyze bankable permits in a framework with incomplete information. Yates and Cronshaw (2001) provide a careful analysis of bankable permits when polluting firms have better information about their abatement costs than does the regulator. They investigate what is the optimal intertemporal trading ratio (ITR) and whether allowing bankable permits is welfare improving given that the bankable permit 
system is optimally designed.

Our work differs from previous studies in the following two aspects. First, we study the efficiency of bankable permit systems. However, instead of focusing on the optimal ITR, we mainly examine two special ITRs that are most likely to be considered by policymakers because of their simplicity: the unitary ITR under which permits in every period are treated the same, and a non-unitary ITR where the interest rate on banked (or borrowed) permits is the same as the monetary interest rate. Using a two-period model, we find that a unitary bankable permit regime can dominate a no-banking regime if the marginal benefit curve is steeper than the marginal damage curve and if uncertainties in the two periods are adequately negatively correlated. We also find that allowing intertemporal trading with an $I T R=1+r$ is always welfare improving as long as the marginal benefit curve is steeper than the marginal damage curve.

Second, we assume there are both uncertainties and asymmetric information. In our model, both firms and the regulator are assumed not to know the shocks in the future. However, only firms are assumed to know the shocks in the current period. The emphasis on the distinction between uncertainty and asymmetric information is important because, as we show later, as firms' information advantage decreases, the gain from allowing intertemporal trading becomes smaller. To the extent that in the real world both firms and the regulator face uncertainties and firms tend to know more about their abatement costs, it is useful that policy analyses on bankable permits actually take into account the distinction.

The rest of this paper is organized as follows. We lay out the basic elements of the model in the next section. In the third section, we examine firms' behaviors in alternative bankable permit regimes. Section 4 examines the unitary and 
non-unitary bankable permit regimes. Section 5 concludes.

\section{Model Setup}

Consider a two-period situation with firms generating pollution as an externality. Since our focus is on intertemporal trading, we assume firms are homogeneous. In particular, we model the firms as one entity, an industry. Firms benefit from emissions. The benefits are equivalent to the saved abatement costs and are subject to a random shock in each period. The shocks could be due to technological progress or fluctuations in the demand for the industry's products or the supply of its inputs. ${ }^{2}$

Let $e_{t}$ be the amount of pollution emissions and $\mu_{t} \backsim\left(0, \sigma_{t}^{2}\right)$ be the random shock in period $t$. Shocks may be persistent, i.e., $\mu_{t}$ could be correlated across time. We denote the benefit function as $B\left(e_{t}, \mu_{t}\right)$, with $B_{e}(\cdot)>0, B_{e e}(\cdot)<0$. The monotonicity and concavity of $B(\cdot)$ are a result of the monotonicity and convexity of the abatement cost function (in the level of abatement). The social damages from emissions are denoted as $D\left(e_{t}\right)$ with $D^{\prime}(\cdot)>0, D^{\prime \prime}(\cdot)>0 .^{3}$ In the absence of government intervention, firms disregard $D(\cdot)$ in their private decisions.

Before the beginning of the first period, the regulator, without knowing the shock in each period, has to determine the total number of permits to be issued for both periods and the intertemporal trading rules. We assume that the regulator is able to commit. That is, after the number of permits and the trading ratio are set, they are then written into law and the regulator cannot change them. This is the case in the $\mathrm{SO}_{2}$ trading program.

At the beginning of period 1 , the shock $\mu_{1}$ occurs and firms observe its realization. They then distribute their permits between the two periods. When firms make their decisions in period 1 , they do not know what the shock $\mu_{2}$ will be 
in the second period. However, they could update their information about the distribution of $\mu_{2}$ based on what they have observed. When shocks are correlated across time, firms, after knowing $\mu_{1}$, may have better information about $\mu_{2}$ than the regulator had when the parameters of the market were set. If the shocks are perfectly correlated, then firms will know exactly what $\mu_{2}$ will be one period before its actual realization.

\section{Firms' Problem}

In designing an optimal bankable permit regime, the regulator needs to take into account how firms behave in such a regime. So, we first derive firms' optimal decisions in a given regime, where the number of permits issued for each period is $\bar{e}_{t}$, and the trading ratio for banked permits is set at $1+\theta$. For every permit banked (borrowed), $1+\theta$ will be available for later use (be repaid), i.e., the interest rate on permits is $\theta$. Then, the firms' problem can be written as

$$
\begin{array}{cl}
\max _{e_{1}, e_{2}} & B\left(e_{1}, \mu_{1}\right)+\frac{1}{1+r} E\left[B\left(e_{2}, \mu_{2}\right) \mid \mu_{1}\right] \\
\text { Such that } & e_{1}+e_{2} \leq \bar{e}_{1}+\bar{e}_{2}+\theta\left(\bar{e}_{1}-e_{1}\right), \quad e_{1}, e_{2} \geq 0
\end{array}
$$

where " $E$ " is the expectation operator. The corresponding optimal condition is

$$
(1+r) \frac{\partial B\left(e_{1}, \mu_{1}\right)}{\partial e_{1}}=(1+\theta) \frac{\partial E\left[B\left(e_{2}, \mu_{2}\right) \mid \mu_{1}\right]}{\partial e_{2}} .
$$

Equation (2) requires that the (adjusted) marginal benefits in the two periods be equal for firms. The marginal benefits in the first period are multiplied by $(1+r)$ because benefits in the first period are worth $(1+r)$ times more than those in the second period because of interest on monetary values. The reason that the expected marginal benefits in the second period are multiplied by $(1+\theta)$ is that one unit of permit saved in the first period will be worth $(1+\theta)$ units of permit in the second period because of interest on permits. 
Rewriting (1b), we get

$$
e_{1}+\frac{e_{2}}{1+\theta} \leq \bar{e}_{1}+\frac{\bar{e}_{2}}{1+\theta}, \quad e_{1}, e_{2} \geq 0
$$

Then, it is easy to see that the parameters that matter are $\theta$ and $\bar{e}$ with

$\bar{e} \equiv \bar{e}_{1}+\frac{1}{1+\theta} \bar{e}_{2}$. In particular, for any given $\bar{e}$ and $\theta$, the values of $\bar{e}_{1}$ and $\bar{e}_{2}$ do not matter. Intuitively, given that firms are allowed to freely substitute permits issued for one period with those issued for another period, the actual number of permits issued for any specific period has little real meaning. From the constraint and the first-order condition, we know in a bankable permit regime that firms' emissions in both periods are functions of $\bar{e}$ and $\theta$ and in general will be different from $\bar{e}_{1}$ and $\bar{e}_{2}$. In the following analysis, we will examine the design of alternative bankable permit regimes.

\section{Alternative Bankable Permit Regimes}

To design an optimal bankable permit regime, the regulator chooses $\theta$ and $\bar{e}$ to maximize the expected benefits minus damages, knowing that firms choose their emission levels $e_{1}(\bar{e}, \theta)$ and $e_{2}(\bar{e}, \theta)$ according to (1b) and (2). Thus, the regulator's problem is

$$
\begin{gathered}
\max _{\bar{e}, \theta} \quad E\left[W\left(e_{1}(\bar{e}, \theta), e_{2}(\bar{e}, \theta)\right)\right] \\
\equiv E\left[B\left(e_{1}(\bar{e}, \theta), \mu_{1}\right)+\frac{1}{1+r} B\left(e_{2}(\bar{e}, \theta), \mu_{2}\right)-D\left(e_{1}(\bar{e}, \theta)\right)-\frac{1}{1+r} D\left(e_{2}(\bar{e}, \theta)\right)\right] \\
\text { such that } \quad \bar{e} \geq 0 .
\end{gathered}
$$

Firms' emissions for each period are fixed when banking is not allowed. In this case, the condition for social welfare maximization is

$$
\frac{\partial E\left[B\left(\bar{e}_{t}^{n b}, \mu_{t}\right)\right]}{\partial e_{t}}=\frac{\partial D\left(\bar{e}_{t}^{n b}\right)}{\partial e_{t}} \quad \forall t=1,2
$$


where the superscript " $n b$ " stands for the ex ante no-banking social optimal level. Equation (4) says that permits in the absence of banking should be set such that the expected marginal benefits equal the marginal damages in each period.

Before proceeding to solve problem (3), we need to know $e_{1}$ and $e_{2}$ as a function of $(\bar{e}, \theta)$. To derive $e_{t}(\bar{e}, \theta)$ and to facilitate the comparison between no banking and banking, we use second-order Taylor expansions ${ }^{4}$ of the benefit and damage functions around the no-banking social optimal, $\bar{e}_{t}^{n b}$, i.e.,

$$
\begin{aligned}
B\left(e_{t}, \mu_{t}\right) & \doteq B_{0}+\left(B_{1}+\mu_{t}\right)\left(e_{t}-\bar{e}_{t}^{n b}\right)-\frac{1}{2} B_{11}\left(e_{t}-\bar{e}_{t}^{n b}\right)^{2} \\
D\left(e_{t}\right) & \doteq D_{0}+D_{1}\left(e_{t}-\bar{e}_{t}^{n b}\right)+\frac{1}{2} D_{11}\left(e_{t}-\bar{e}_{t}^{n b}\right)^{2}
\end{aligned}
$$

where $B_{0}, B_{1}, B_{11}$ and $D_{0}, D_{1}, D_{11}$ are fixed coefficients with $B_{1}>0, B_{11} \geq 0$, $D_{1}>0, D_{11} \geq 0$. Uncertainty is assumed to affect the marginal benefit function by shifting it up or down, while keeping its slope unchanged. By (4), we know $B_{1}=D_{1}$.

To simplify notation, we define the following.

Definition 1 Firms' demand for banking ${ }^{5}$ in period $t$ is defined as the difference between the demand for permits in a banking regime and the no-banking optimal permits, i.e., $\Delta e_{t} \equiv e_{t}(\bar{e}, \theta)-\bar{e}_{t}^{n b}$.

Solving (1) with (5a), we get

$$
\begin{aligned}
\Delta e_{1}(\bar{e}, \theta) & =\frac{(1+r)\left(B_{1}+\mu_{1}\right)-(1+\theta)\left(B_{1}+E\left[\mu_{2} \mid \mu_{1}\right]\right)}{B_{11}\left[(1+r)+(1+\theta)^{2}\right]}+\frac{(1+\theta)^{2} \Delta \bar{e}}{(1+r)+(1+\theta)^{2}} \\
\frac{\Delta e_{2}(\bar{e}, \theta)}{(1+\theta)} & =\frac{-(1+r)\left(B_{1}+\mu_{1}\right)+(1+\theta)\left(B_{1}+E\left[\mu_{2} \mid \mu_{1}\right]\right)}{B_{11}\left[(1+r)+(1+\theta)^{2}\right]}+\frac{(1+r) \Delta \bar{e}}{(1+r)+(1+\theta)^{2}}
\end{aligned}
$$

where $\Delta \bar{e} \equiv \bar{e}-\bar{e}^{n b}, \bar{e}=\bar{e}_{1}+\frac{1}{1+\theta} \bar{e}_{2}$, and $\bar{e}^{n b}=\bar{e}_{1}^{n b}+\frac{1}{1+\theta} \bar{e}_{2}^{n b}$. On the left of the second equation, $\frac{1}{(1+\theta)}$ is used to convert the second-period emissions into their present discounted value, making them comparable to $\Delta e_{1}(\bar{e}, \theta)$. 
Given $1+\theta$ and $\Delta \bar{e}$, firms' demand for banking in each period depends on four factors. The first is the slope of the marginal benefit curve $\left(B_{11}\right)$. The flatter the marginal benefit curve is, the more emissions in each period in a bankable permit regime deviate from the no-banking optimal emissions. The second is the difference between total permits in a bankable permit regime and the no-banking regime $(\Delta \bar{e})$. Whenever $\Delta \bar{e}>0($ or $<0)$, firms will split the difference between the two periods to equalize marginal benefits across time. The third is the relative magnitudes of (expected) marginal benefits evaluated at the no-banking optimum, i.e., $B_{1}+\mu_{1}$,

and $B_{1}+E\left[\mu_{2} \mid \mu_{1}\right]$. If marginal benefits in the first period adjusted by $(1+r)$ are higher than the expected marginal benefits in the second period adjusted by $(1+\theta)$, then first period emissions tend to be higher. Lastly, if $\mu_{1}$ and $\mu_{2}$ are negatively correlated, i.e., they tend to have opposite signs, their effects tend to enhance each other. Otherwise, their effects tend to cancel each other.

\section{Optimal total permits}

Substituting (6a)-(6b) into (3), we can derive the optimal $\bar{e}$ and $\theta$. We approach the problem in two steps. We first solve the optimal $\Delta \bar{e}$ for a given $\theta$, and then discuss the effects of alternative values of $\theta$.

Solving (3) for any given $\theta$, we have the following.

Proposition 1 The optimal total permits in a bankable permit regime with any intertemporal trading ratio equal the total optimal permits in a no-banking regime; that is, $\bar{e}=\bar{e}^{n b}$, or $\Delta \bar{e}=0, \forall \theta$.

The result is due to the way firms distribute the difference $\Delta \bar{e}$ between the two periods. Firms distribute the extra permits across the two periods such that marginal benefits in the two periods remain equal. From (6), we know for any $\Delta \bar{e}$, 
no matter what the realizations of the shocks are, firms allocate $\frac{(1+\theta)^{2}}{(1+r)+(1+\theta)^{2}} \Delta \bar{e}$ to the first period and $\frac{(1+r)}{(1+r)+(1+\theta)^{2}} \Delta \bar{e}$ to the second period. This implies that, setting $\Delta \bar{e} \neq 0$ does not help adjust firms' distribution of emissions toward what is socially optimal. Therefore, there is no reason to set $\Delta \bar{e}$ different from zero.

Proposition 1 has one interesting policy implication: at least in terms of the total number of permits, the design of a bankable permit regime is no more complicated than that of a no-banking regime. We next discuss the other parameter of a bankable permit regime, the intertemporal trading ratio, and compare the welfare effects of different permit trading regimes.

\section{Unitary bankable permit regime}

For a unitary bankable permit regime, $\theta$ is set to zero, meaning that firms can bank or borrow permits across time periods at a one-for-one rate. As to the number of total permits, from Proposition 1, we know $\bar{e}^{u b}=\bar{e}^{n b}$ or $\Delta \bar{e}=0$. Substituting $\theta=0$ and $\Delta \bar{e}=0$ into (6), we get firms' demand for banking in a unitary bankable permit regime:

$$
\begin{aligned}
\Delta e_{1}^{u b}\left(\bar{e}^{u b}, 0\right) & =\frac{r B_{1}+(1+r) \mu_{1}-E\left[\mu_{2} \mid \mu_{1}\right]}{(2+r) B_{11}}, \\
\Delta e_{2}^{u b}\left(\bar{e}^{u b}, 0\right) & =\frac{-r B_{1}-(1+r) \mu_{1}+E\left[\mu_{2} \mid \mu_{1}\right]}{(2+r) B_{11}}
\end{aligned}
$$

where the superscript " $u b$ " stands for unitary banking. The explanation for $(7)$ is the same as in (6) except that here the weight on the marginal benefits in the second period is 1 instead of $1+\theta$. When there is no uncertainty, the demand for banking is

$$
\Delta e_{1}^{u b}\left(\bar{e}^{u b}, 0\right)=\frac{r B_{1}}{(2+r) B_{11}}, \quad \Delta e_{2}^{u b}\left(\bar{e}^{u b}, 0\right)=\frac{-r B_{1}}{(2+r) B_{11}}, \text { for } \mu_{1}=\mu_{2}=0
$$

Thus in the absence of uncertainty, if permits for each period are set at the no-banking optimum, firms will desire borrowing. This point is made by Kling and 
Rubin (1997), who find that in many cases firms would choose suboptimally excessive emission levels in early periods and correspondingly too few in later periods given the opportunity to freely move emissions between time periods. This is because firms discount future benefit streams and disregard the social damages of their emissions. Equation (8) quantifies this effect. For comparison with later analysis, we illustrate the case in Figure 1.

In Figure $1, M B$ and $M D$ are the marginal benefit and damage functions. When there is no uncertainty, social optimality, which is also the no-banking optimum, requires that $M B\left(\bar{e}_{1}^{n b}\right)=M D\left(\bar{e}_{1}^{n b}\right)$ and $M B\left(\bar{e}_{2}^{n b}\right)=M D\left(\bar{e}_{2}^{n b}\right)$, implying $\bar{e}_{1}^{n b}=\bar{e}_{2}^{n b}\left(=e^{n b}\right)$. However, if the regulator is going to issue permits equal to the no-banking optimal levels and then let firms trade with $\mathrm{ITR}=1$, then the emission levels are $e_{1}^{u b}$ and $e_{2}^{u b}$, with $e_{1}^{u b}>\bar{e}_{1}^{n b}, e_{2}^{u b}<\bar{e}_{2}^{n b}$, and $e_{1}^{u b}-e^{n b}=e^{n b}-e_{2}^{u b}$. When firms have the freedom to adjust their emissions through time, they will find $\bar{e}_{1}^{n b}$ and $\bar{e}_{2}^{n b}$ suboptimal, because by moving some emissions from period 2 to period 1 the additional benefits in period 1 will outweigh the reduced benefits in period 2 .

When there is uncertainty, from $\Delta e_{1}^{u b}(\cdot)$ and $\Delta e_{2}^{u b}(\cdot)$ in $(7)$, we know that the higher is the (conditional) expectation of second period shock, the lower are the first-period emissions. However, it is not clear how firms' demand for permits will differ from the no-banking optimum because the relative magnitude of the uncertain terms is not known ex ante.

Definition 2 Define the relative efficiency of a bankable permit regime as the welfare difference between a bankable permit regime and the no-banking regime, i.e., $\Delta E[W(\bar{e}, \theta)] \equiv E\left[W\left(e_{1}(\bar{e}, \theta), e_{2}(\bar{e}, \theta)\right)\right]-E\left[W\left(\bar{e}_{1}^{n b}, \bar{e}_{2}^{n b}\right)\right]$

Substituting (7) into the welfare function in (3) and then comparing it with the 
no-banking welfare level, we get

$$
\Delta E\left[W^{u b}\left(\bar{e}^{u b}, 0\right)\right]=\frac{-\left(B_{11}+D_{11}\right)\left(r B_{1}\right)^{2}}{2(1+r)(2+r) B_{11}^{2}}+\frac{\left(B_{11}-D_{11}\right) E\left[(1+r) \mu_{1}-E\left(\mu_{2} \mid \mu_{1}\right)\right]^{2}}{2(1+r)(2+r) B_{11}^{2}} .
$$

The first term is negative, which is equal to the sum of the two shaded areas in Figure 1 and represents the welfare loss (compared to a no-banking regime) in the case absent uncertainty. The slope of the marginal benefit curve has two effects on the first term. On the one hand, as we discussed before, a flatter marginal benefit function means that a bigger emissions adjustment is needed to equalize marginal benefits across time. Since permits issued for each period are optimal in the absence of uncertainty, we want the adjustment of emissions as small as possible. In this sense, a steeper marginal benefit function will result in less loss, which is captured by $B_{11}^{2}$ in the denominator. On the other hand, for any given amount of emissions deviating from the optimal, we want both the marginal benefit and damage functions to be flatter, which is indicated by the presence of $\left(B_{11}+D_{11}\right)$ in the numerator. From (8), we also know that the higher are the marginal benefits, the more emissions in the two periods will differ, which in turn means more loss will occur. This explains the term $\left(r B_{1}\right)^{2}$ in the numerator.

The second term captures the welfare effects of uncertainty, which cannot be unambiguously signed (and is not shown in Figure 1). It will be positive if the marginal benefit curve is steeper than the marginal damage curve. Taking expectations, we have $E\left[(1+r) \mu_{1}-E\left(\mu_{2} \mid \mu_{1}\right)\right]^{2}=(1+r)^{2} \sigma_{1}^{2}-2(1+r) \sigma_{12}+\sigma_{2 \mid 1}^{2}$, where $\sigma_{1}^{2}, \sigma_{12}$ and $\sigma_{2 \mid 1}^{2}$ are the variance of $\mu_{1}$, the covariance of $\mu_{1}$ and $\mu_{2}$, and the variance of the conditional expectation of $\mu_{2}$, respectively. That is, $\sigma_{1}^{2}=E\left[\mu_{1}\right]^{2}$, $\sigma_{12}=E\left[\mu_{1} \mu_{2}\right]$, and $\sigma_{2 \mid 1}^{2}=E\left[E\left(\mu_{2} \mid \mu_{1}\right)\right]^{2}$. Thus, the absolute value of the second term in (9) will be larger if $\mu_{1}$ and $\mu_{2}$ have larger variances and/or are negatively correlated. 
The factor $B_{11}-D_{11}$ in the second term in (9) is the comparison of the slopes of the marginal benefit and marginal damage curves, which resembles the comparison of slopes in Weitzman's (1974) analysis on price versus quantity tools. The no-banking regime is a quantity tool since it fixes emissions in each period, just as a standard fixes the emissions for each firm. A bankable permit regime is akin to a price system in that emission levels in each period can be adjusted. ${ }^{6}$ Weitzman (1974) shows that whether a price tool dominates a quantity tool depends on the slopes of the marginal benefit and damage functions. Similarly, whether a bankable permit regime dominates a no-banking regime depends on the slopes of marginal benefit and damage functions. In both cases, how much one is preferred to the other depends on the covariance structure of the shocks.

Intuitively, a unitary bankable permit regime could be welfare enhancing because it gives firms who have better information about the random shocks the flexibility of adjusting to shocks. However, since firms ignore the social damages, their adjustment may be suboptimal. Therefore, how a unitary permit regime performs relative to a no-banking regime depends on how much there is to gain from flexibility (the second term) relative to how severely firms' redistribution of permits differs from the social optimal (the first term). In other words, directly from (9), we have the following.

Proposition 2 A unitary bankable permit trading regime dominates a no-banking regime if

$$
\left(B_{11}-D_{11}\right) E\left[(1+r) \mu_{1}-E\left(\mu_{2} \mid \mu_{1}\right)\right]^{2}>\left(D_{11}+B_{11}\right)\left(r B_{1}\right)^{2} .
$$

For a unitary bankable regime to dominate a no-banking regime, the condition that the marginal benefit curve is steeper than the marginal damage curve is necessary but not sufficient. In particular, the covariance structure of the shocks is 
important. The more shocks are negatively correlated, the more likely that a unitary bankable regime will dominate a no-banking regime.

Figure 2 illustrates a case where a unitary bankable regime dominates a no-banking regime. In the figure, the no-banking optimum requires that $E\left[M B\left(\bar{e}_{1}^{n b}\right)\right]=\left[M D\left(\bar{e}_{1}^{n b}\right)\right]$ and $E\left[M B\left(\bar{e}_{2}^{n b}\right)\right]=\left[M D\left(\bar{e}_{2}^{n b}\right)\right] ;$ that is, the expected marginal benefits and marginal damages are equal in each period. This in turn implies $\bar{e}_{1}^{n b}=\bar{e}_{2}^{n b}=e^{n b}$. As indicated in the figure, in the first period, firms observe the realization of $\mu_{1}>0$ and expect the shock in the second period to be $E\left[\mu_{2} \mid \mu_{1}\right]<0$. Then they distribute their emissions in the two periods as $e_{1}^{u b}$ and $e_{2}^{u b}$, such that expected marginal benefits are equalized across the two periods, i.e., $M B\left(e_{1}^{u b} ; \mu_{1}\right)=\frac{E\left[M B\left(e_{2}^{u b} ; \mu_{1}\right)\right]}{1+r}$. Since it turns out that abatement costs in the first period are very high and are expected to be relatively low in the second, firms emit more in the first and correspondingly fewer in the second period.

Given the information in the first period, to achieve the expected social optimum, which requires $M B\left(e_{1} ; \mu_{1}\right)=M D\left(e_{1} ; \mu_{1}\right)$ and $E\left[M B\left(e_{2} ; \mu_{1}\right)\right]=M D\left(e_{2}\right)$, the emissions would have been $e_{1}^{*}$ and $e_{2}^{*}$. Without intertemporal trading, the social loss would be the areas of the two dotted triangles because of too few emissions in the first period and too many in the second. With intertemporal trading, the social loss would be the areas of the two bold-line bordered triangles because of too many emissions in the first period and too few in the second. Neither regime attains $e_{1}^{*}$ and $e_{2}^{*}$. When the condition in Proposition 2 is satisfied, the loss of a no-banking regime is greater than that of a unitary bankable permit system, as shown in the figure.

There is also an alternative interpretation for Figure 2. Compared to the no-banking regime, firms gain from additional emissions in the first period and lose 
because of reduced emissions in the second. The opposite is true on the damage side; there are more (fewer) damages in the first (second) period. In the figure, the benefit gain outweighs the increase in damages.

\section{Non-unitary bankable permit regimes}

Instead of fixing $\theta$ at zero, the regulator can choose $\theta$ as well as $\bar{e}$ to maximize social welfare. From Proposition 1, we know $\bar{e}^{g b}=\bar{e}^{n b}$, or $\Delta \bar{e}=0$. Then from (6), we get firms' demand for banking in a non-unitary bankable permit regime:

$$
\begin{aligned}
\Delta e_{1}^{g b}\left(\bar{e}^{g b}, \theta\right) & =\frac{(r-\theta) B_{1}+(1+r) \mu_{1}-(1+\theta) E\left[\mu_{2} \mid \mu_{1}\right]}{\left[(1+r)+(1+\theta)^{2}\right] B_{11}}, \\
\frac{\Delta e_{2}^{g b}\left(\bar{e}^{g b}, \theta\right)}{(1+\theta)} & =\frac{-(r-\theta) B_{1}-(1+r) \mu_{1}+(1+\theta) E\left[\mu_{2} \mid \mu_{1}\right]}{\left[(1+r)+(1+\theta)^{2}\right] B_{11}}
\end{aligned}
$$

where the superscript " $g b$ " stands for a general bankable permit regime with ITR

not necessarily equal to zero. Substituting these demand functions into the welfare function in (3), we get

$$
\begin{gathered}
\Delta E\left[W^{g b}\left(\bar{e}^{g b}, \theta\right)\right]=\Delta W_{c}^{g b}\left(\bar{e}^{g b}, \theta\right)+\Delta W_{u c}^{g b}\left(\bar{e}^{g b}, \theta\right), \text { with } \\
\Delta W_{c}^{g b}\left(\bar{e}^{g b}, \theta\right)=\frac{-\left(B_{11}+D_{11}\right)(\theta-r)^{2} B_{1}^{2}}{2(1+r)\left[(1+r)+(1+\theta)^{2}\right] B_{11}^{2}}, \\
\Delta W_{u c}^{g b}\left(\bar{e}^{g b}, \theta\right)=\frac{\left(B_{11}-D_{11}\right) E\left[(1+r) \mu_{1}-(1+\theta) E\left(\mu_{2} \mid \mu_{1}\right)\right]^{2}}{2(1+r)\left[(1+r)+(1+\theta)^{2}\right] B_{11}^{2}}
\end{gathered}
$$

where subscripts " $c$ " and " $u c$ " stand for certain and uncertain, respectively. By maximizing $\Delta E\left[W^{g b}\left(\bar{e}^{g b}, \theta\right)\right]$ with respect to $\theta$, we can get the optimal $\theta, \theta^{g b}$. The optimal solution $\theta^{g b}$ is a complex function of parameters because of the complexity of $\Delta E\left[W^{g b}\left(\bar{e}^{g b}, \theta\right)\right]$. This limits the applicability of $\theta^{g b}$ in reality. Thus, instead of searching for $\theta^{g b}$, we focus on one value of $\theta, \theta=r$, which is more likely to be adopted by policymakers. In particular, we examine how banking with ITR $=1+\mathrm{r}$ compares with no banking and unitary banking. First, we have the following. 
Proposition 3 A bankable permit trading regime with $\theta=r, \bar{e}=\bar{e}^{n b}$ always weakly dominates a no-banking regime given that $\left(B_{11}-D_{11}\right)>0$.

The proof is trivial. Substituting $\theta=r$ into $\Delta E\left[W^{g b}\left(\bar{e}^{g b}, \theta\right)\right]$, we get $\Delta E\left[W^{g b}\left(\bar{e}^{g b}, \theta\right)\right]=\Delta W_{u c}^{g b}\left(\bar{e}^{g b}, \theta\right)$. If $\left(B_{11}-D_{11}\right)>0$, then $\Delta E\left[W^{g b}\left(\bar{e}^{g b}, \theta\right)\right] \geq 0$.

This finding has very important practical implications: if we are not sure what the optimal $\theta$ is, or just for the sake of simplicity, the regulator may set the interest rate on banked permits equal to the interest rate on monetary values. By doing so, she can be sure the bankable permit regime performs better than a no-banking regime given that the slope condition is satisfied and $\bar{e}=\bar{e}^{n b}$. The intuition underlying this is that, by setting $\theta=r$, the regulator offsets firms' tendency to suboptimally distribute permits and still provides firms the flexibility to adjust emissions. Given that the marginal benefit curve is steeper, the benefit gain from adjusting to uncertainty outweighs the damage loss. Thus, setting $\theta=r$ is welfare improving.

Remark 1 An optimal bankable permit trading regime always weakly dominates a no-banking regime if $\left(B_{11}-D_{11}\right)>0$.

The remark is a direct result of Proposition 3. Given that a bankable permit regime with $\theta=r, \bar{e}=\bar{e}^{n b}$ is not necessarily the optimal choice, the actual optimal choice can be no worse. This remark is consistent with one of the findings of Yates and Cronshaw (2001).

Remark 2 Given $\left(B_{11}-D_{11}\right)>0$, a non-unitary bankable permit trading regime with $\theta=r$ does not necessarily dominate a unitary bankable regime.

If $\left(B_{11}-D_{11}\right)>0$, the regime with $I T R=1+r$ is always better than a no-banking regime while a unitary regime can also be better than a no-banking 
regime under the condition in Proposition 2. However, it is not immediately clear which is better, since both of them are suboptimal settings. The answer depends on the structure of the benefit and damage functions and the covariance structure of the shocks. From (9) and (11), we expect the regime with $I T R=1+r$ to be better if the optimal $\theta$ is close to $r$ and the loss from not correcting firms' suboptimal discounting behavior is big.

From (9) and (11), we know the following.

Remark 3 Ceteris paribus, the more shocks are negatively correlated, and/or the more they vary, the higher (lower) is the welfare of a bankable permit trading regime if $\left(B_{11}-D_{11}\right)>0\left(\left(B_{11}-D_{11}\right)<0\right)$. However, the covariance structure of the shocks does not determine whether a bankable regime is better than a no-banking regime, although it affects the magnitude of the difference.

It is easy to see that the value of $E\left[(1+r) \mu_{1}-(1+\theta) E\left(\mu_{2} \mid \mu_{1}\right)\right]^{2}$ is higher, if $\mu_{1}$ and $\mu_{2}$ are negatively correlated. Intuitively, the flexibility provided by intertemporal trading has higher value if it turns out the abatement costs (potential benefits to firms from more emissions) are high in one period and low in another period. Otherwise, firms do not gain much from emissions smoothing. When $\left(B_{11}-D_{11}\right)>0$, the gain for firms from banking outweighs the social loss from the damages of emissions. However, if $\left(B_{11}-D_{11}\right)<0$, then the opposite is true. In this case, the more firms trade, the more are the damages from emissions, which outweigh firms' gain from trading. Thus, the more firms trade, the more is the social loss.

We have analyzed the case where the regulator does not know shocks in both periods when designing a permit trading regime while firms know the first period shock when making emissions decisions. We may also consider situations without 
asymmetric information, i.e., firms and the regulator have the same information, including when both sides know the shocks in each period, when they know the first-period shock but not the second, or when they do not know the shocks in either period. For situations where firms have better information than does the regulator, in addition to the case we have considered in the previous sections, we may also consider the case where firms know the shocks in both periods while the regulator knows neither of them. For bankable permits in these various cases, we have the following proposition.

Proposition 4 With or without uncertainty, if the regulator and firms have the same information about the shocks in the two periods, then the optimal ITR equals $r$ and there is no welfare gain from banking. If firms have better information than the regulator, then whether there is a gain from banking depends on the slopes of the marginal benefit and marginal damage functions, and the magnitude of gain or loss is increasing with the degree of asymmetric information.

For a proof see the appendix. The motivation for allowing firms to trade permits across time is to provide them the flexibility of adjusting to situations which they know better than the regulator. If firms have no better information than the regulator does when they are making their emissions decisions, giving flexibility to them will not result in higher welfare and may well result in lower welfare since firms disregard the externality caused by their emissions.

\section{Conclusions}

This paper studies the design and efficiency of alternative bankable permit regimes. Similar to Yates and Cronshaw (2001), we find that a necessary condition for banking to dominate no banking is that the marginal benefit curve is steeper 
than the marginal damage curve. When this necessary condition is satisfied, whether banking dominates no banking depends on the ITR. Two of our findings are of particular interest.

One is related to bankable permit regimes with $\mathrm{ITR}=1+\mathrm{r}$. When the slope condition is satisfied, a bankable permit regime with total permits equal to the no-banking optimum and ITR $=1+\mathrm{r}$ always dominates no banking. We consider this result interesting because it demonstrates that the design of a welfare-improving bankable permit regime is no more complicated than the no-banking regime.

The other is related to bankable permit regimes with $\mathrm{ITR}=1$. Previous studies (e.g. Kling and Rubin, 1997) have shown that such regimes are suboptimal. We find that this does not necessarily mean that a unitary bankable permit regime should not be used. As long as the flexibility of banking provides more benefit gains than damage losses, unitary banking dominates no banking. This case is more likely to be true when firms have a large information advantage over the regulator about their benefits and benefits tend to be negatively correlated across time. We consider this result interesting because it reveals something about the permit regime which is often actually used. 


\section{Appendix}

\section{Proof for Proposition 4}

(i) When the regulator and firms have the same information

By the definitions of $W(\bullet)$ (see equations (3)) and the benefit and damage functions (see equations (5)), we can write the difference between banking and no banking as

$$
\begin{aligned}
\Delta\left[W^{g b}\left(\bar{e}^{g b}, \theta\right)\right]= & \left(B_{1}+\mu_{1}\right) \Delta e_{1}^{g b}-\frac{1}{2} B_{11}\left(\Delta e_{1}^{g b}\right)^{2}-D_{1} \Delta e_{1}^{g b}-\frac{1}{2} D_{11}\left(\Delta e_{1}^{g b}\right)^{2}+ \\
& \frac{1}{1+r}\left[\left(B_{1}+\mu_{2}\right) \Delta e_{2}^{g b}-\frac{1}{2} B_{11}\left(\Delta e_{2}^{g b}\right)^{2}-D_{1} \Delta e_{2}^{g b}-\frac{1}{2} D_{11}\left(\Delta e_{2}^{g b}\right)^{2}\right] .
\end{aligned}
$$

Taking expectation, we have

$$
\begin{gathered}
\Delta E\left[W^{g b}\left(\bar{e}^{g b}, \theta\right)\right]= \\
\left(B_{1}+z_{1}\right) E\left[\Delta e_{1}^{g b}\right]-\frac{1}{2} B_{11} E\left[\left(\Delta e_{1}^{g b}\right)^{2}\right]-D_{1} E\left[\Delta e_{1}^{g b}\right]-\frac{1}{2} D_{11} E\left[\left(\Delta e_{1}^{g b}\right)^{2}\right]+ \\
\frac{1}{1+r}\left[\left(B_{1}+z_{2}\right) E\left[\Delta e_{2}^{g b}\right]-\frac{1}{2} B_{11} E\left[\left(\Delta e_{2}^{g b}\right)^{2}\right]-D_{1} E\left[\Delta e_{2}^{g b}\right]-\frac{1}{2} D_{11} E\left[\left(\Delta e_{2}^{g b}\right)^{2}\right]\right],
\end{gathered}
$$

where the terms $z_{1}$ and $z_{2}$ take on different forms depending on how much information the regulator and firms have. If the regulator and firms know the shocks in both periods, then $z_{1}=\mu_{1}$, and $z_{2}=\mu_{2}$. If they only know the shocks in the first period, then $z_{1}=\mu_{1}$, and $z_{2}=E\left[\mu_{2} \mid \mu_{1}\right]$. If they know the shock in neither period, then $z_{1}=E\left[\mu_{1}\right]=0$, and $z_{2}=E\left[\mu_{2}\right]=0$. (The shocks in $\Delta e_{t}^{g b}$, as given in (10), also vary depending the information known by the regulator and firms.) Given $\Delta e_{t}^{g b} \equiv e_{t}^{g b}-\bar{e}_{t}^{n b}$ and the optimal conditions for no banking, we know

$$
B_{1}+z_{1}=D_{1}, \quad \text { and } B_{1}+z_{2}=D_{1}
$$


Thus, the terms linear in $\Delta e_{t}^{g b}$ drop out and we have

$$
\begin{aligned}
\Delta E\left[W^{g b}\left(\bar{e}^{g b}, \theta\right)\right]= & -\frac{1}{2} B_{11} E\left[\left(\Delta e_{1}^{g b}\right)^{2}\right]-\frac{1}{2} D_{11} E\left[\left(\Delta e_{1}^{g b}\right)^{2}\right] \\
& -\frac{1}{2(1+r)} B_{11} E\left[\left(\Delta e_{2}^{g b}\right)^{2}\right]-\frac{1}{2(1+r)} D_{11} E\left[\left(\Delta e_{2}^{g b}\right)^{2}\right] .
\end{aligned}
$$

To further simplify, we know from $(10)$ that $\Delta e_{2}^{g b}\left(\bar{e}^{g b}, \theta\right)=-(1+\theta) \Delta e_{1}^{g b}\left(\bar{e}^{g b}, \theta\right)$. Then rearranging the above equation, we obtain

$$
\Delta E\left[W^{g b}\left(\bar{e}^{g b}, \theta\right)\right]=\frac{-1}{2(1+r)}\left(B_{11}+D_{11}\right)\left[(1+r)+(1+\theta)^{2}\right] E\left[\left(\Delta e_{1}^{g b}\right)^{2}\right] .
$$

By examining (10a), we know $E\left[\left(\Delta e_{1}^{g b}\right)^{2}\right]$ achieves minimal value (zero) at $\theta=r$, since $(\mathrm{A}-1)$ implies $z_{1}=z_{2}$. Given that $\Delta E\left[W^{g b}\left(\bar{e}^{g b}, \theta\right)\right] \leq 0$, setting $\theta=r$ maximizes it.

(ii) When firms have better information

Most of the analysis in the paper deals with the case where the regulator does not know the shocks in both periods while firms know the shocks in the first period but not in the second. So here we will only analyze the case where the regulator still does not know the shock in either period while firms know the shocks in both periods. In this case, we say the degree of asymmetric information increases (relative to the case focused on in the paper) because firms' information has improved while the regulator's stays the same. When firms know $\mu_{2}$, the conditional expectation term in $(6), E\left[\mu_{2} \mid \mu_{1}\right]$, will be replaced by $\mu_{2}$. And $E\left[(1+r) \mu_{1}-\right.$ $\left.(1+\theta) E\left(\mu_{2} \mid \mu_{1}\right)\right]^{2}$, in $\Delta E\left[W^{g b}\left(\bar{e}^{g b}, \theta\right)\right]$ will be replaced by $E\left[(1+r) \mu_{1}-(1+\theta) \mu_{2}\right]^{2}$. Since $E\left[(1+r) \mu_{1}-(1+\theta) E\left(\mu_{2} \mid \mu_{1}\right)\right]^{2}-E\left[(1+r) \mu_{1}-(1+\theta) \mu_{2}\right]^{2}=\sigma_{2 \mid 1}^{2}-\sigma_{2}^{2} \leq 0$, the second half of the remark follows. 


\section{References}

Carlson, C., D. Burtraw, M. Cropper, amd K. Palmer. 2000. "Sulfur Dioxide Control by Electric Utilities: What Are the Gains from Trade?" Journal of Political Economy 108 (6): 1292-1326.

Cronshaw, M.B., and J.B. Kruse. 1996. "Regulated Firms in Pollution Permit Markets with Banking." Journal of Regulatory Economics 9: 179-189.

Ellerman, D., R. Schmalensee, P. Joskow, J. Montero, and E. Bailey. 2000. Markets for Clean Air: the U.S. Acid Rain Program. Cambridge, UK: Cambridge University Press.

Farrell, A., R. Carter, and R. Raufer. 1999. "The $\mathrm{NO}_{x}$ Budget: Market-Based Control of Tropospheric Ozone in the Northeastern United States." Resource and Energy Economics 21 (2): 103-124.

Hoel, M., and L. Karp. 2002. "Taxes Versus Quotas for a Stock Pollutant." Resource and Energy Economics (forthcoming).

—. 2001. "Taxes Versus Quotas for a Stock Pollutant with Multiple Uncertainty." Journal of Public Economics 82: 91-114.

Kerr, S., and D. Maré. 1996. "Efficient Regulation Through Tradeable Permit Markets: The United States Lead Phasedown." WP 96-06, Department of Agricultural and Resource Economics, University of Maryland.

Kling, C., and J.D. Rubin. 1997. "Bankable Permits for the Control of Environmental Pollution." Journal of Public Economics 64: 101-115.

Kolstad, C.D. 1987. "Uniformity versus Differentiation in Regulating Externalities." Journal of Environmental Economics and Management 14: 386-399.

Leiby, P., Rubin, J.D., 2001. "Bankable Permits for the Control of Stock and Flow Pollutants: Optional Intertemporal Greenhouse Gas Emission Trading.” Environmental and Resource Economics 19 (3): 
229-256.

Montgomery, W. D. 1972. "Markets in Licenses and Efficient Pollution Control Programs." Journal of Economic Theory 5: 395-418,

Newell, R.G., and W.A. Pizer. 2002. "Regulating Stock Externalities Under Uncertainty." Journal of Environmental Economics and Management (forthcoming).

Rubin, J.D. 1996. "A Model of Intertemporal Emission Trading, Banking, and Borrowing." Journal of Environmental Economics and Management 31: 269-286.

Rubin, J.D., C. KlingC. 1993. "An Emission Saved is an Emission Earned: an Empirical Study of Emission Banking for Light-Duty Vehicle Manufacturers." Journal of Environmental Economics and Management 25: 257-274.

Stavins, N.R. 1996. “Correlated Uncertainty and Policy Instrument Choice.” Journal of Environmental Economics and Management 30: 218-232.

—. 1998. "What Can We Learn From the Grand Policy Experiment? Lessons from $\mathrm{SO}_{2}$ Allowance Trading." Journal of Economic Perspectives 12 (3): 69-88.

—. 2002. "Experience with Market-Based Environmental Policy Instruments." In The Handbook of Environmental Economics (chapter 21), K-G., Mäler, and J. Vincent, eds. Amsterdam: North-Holland/Elsevier Science. (forthcoming).

Tietenberg, T. (Ed.), 2001. Emissions Trading Programs, Volumns 1 and 2. Burlington, Vt: Ashgate Publishing Company.

Weitzman, M.L. 1974. "Prices versus Quantities." Review of Economic Studies 41: 477-491.

Yates, A.J., and M.B. Cronshaw. 2001. "Pollution Permit Markets with Intertemporal Trading and Asymmetric Information.” Journal of Environmental Economics and Management 42: 104-118. 


\section{Endnotes}

${ }^{1}$ For a comprehensive description of permit trading programs, see Stavins (2002).

${ }^{2}$ For example, the current marginal abatement costs for $\mathrm{SO}_{2}$ are much lower than were estimated ten years ago. Over the decade preceding 1995, a typical unit's marginal abatement cost function was lowered by almost $\$ 50$ dollars per ton of $\mathrm{SO}_{2}$ by technical improvements including advances in the ability to burn low-sulfur coal at existing generators, as well as improvements in overall generating efficiency. Moreover, the decline in fuel costs lowered the marginal abatement costs by about $\$ 200$ per ton (Carlson et al., 2000).

${ }^{3}$ Montgomery (1972) formally establishes the monotonicity and convexity of the abatement cost function. Uncertainty in the damage function will affect our results only if it is correlated with uncertainty in the benefit function. Stavins (1996) provides an analysis of policy instrument choice when uncertainties are correlated.

${ }^{4}$ The "accurate local approximation" is very similar to what is originally used in Weitzman (1974) and since then has been widely used in other studies; for example, Kolstad (1987), Hoel and Karp (2001, 2002), and Newell and Pizer (2002). As it will become clear later, using this kind of approximation allows us to connect our study with Weitzman's (1974) study.

${ }^{5}$ For any given $\bar{e}$ and $\theta$, firms' demand for banking in any period has a one-to-one relationship with the number of permits actually issued for this period. If the number of permits in a period increases by one then the demand for banking in this period decreases by one. Thus, to focus on other factors affecting banking, we study demand for banking when the number of permits issued is equal to the no-banking optimum.

${ }^{6}$ Another way to think about this is that given total permits available, once firms know the shock in the first period and make their best guess about the shock in the second period, the permit prices in the two periods are given. Thus, when firms make their emission decisions, it is as if they faced a fixed price. 


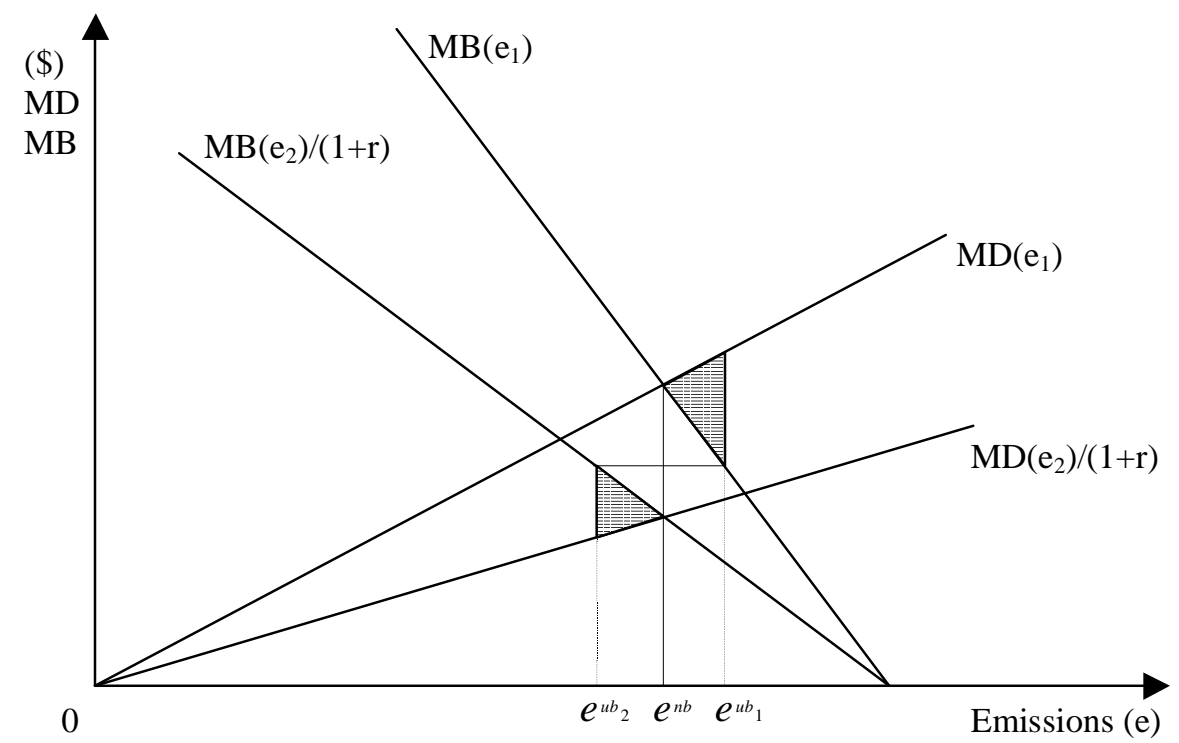

Figure 1: Emissions and Welfare-

Banking with ITR $=1$ and No Uncertainty 


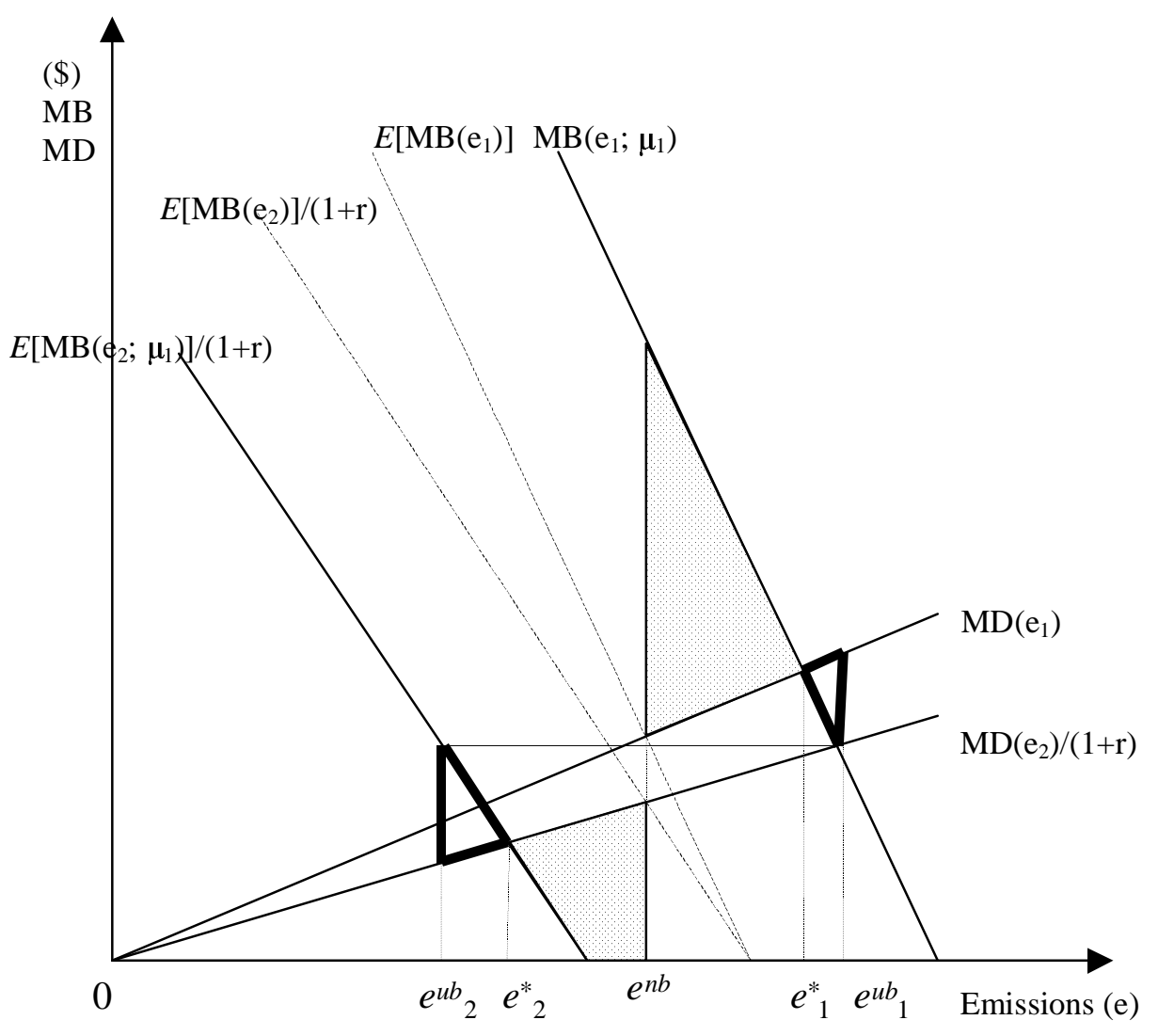

Figure 2: Emissions and Welfare-

Banking with ITR=1 and Uncertainty 